\title{
Commentary on C. Trevor \& D. Huron Are Humoresques Humorous? On the Similarity Between Laughter and Staccato
}

\author{
JÖRG MÜHLHANS[1] \\ University of Vienna
}

\begin{abstract}
This commentary discusses and comments on the study by Trevor and Huron on the acoustical similarities between human laughter and staccato articulation in music.
\end{abstract}

Submitted 2018 August 21; accepted 2018 October 15.

KEYWORDS: humor in music, instrumentation, musical expression

IN their study, Trevor and Huron propose an interesting link between human laughter and staccato, a form of musical articulation. Two theories are suggested: On the one hand, composers are said to use this musical articulation to portray laughter in humorous pieces of music. On the other hand, the authors claim, portrayed laughter is authentic, if tempo and duty cycle of the staccato match those of real laughter. The two parts of this study are connected, but do not necessarily depend on each other, since portrayed emotions in music are rather exaggerated than authentic.

Part two of the study shall be discussed first, because the music theory of figures and articulations is crucial for understanding the expression of emotions, gestures and alike.

A brief historical overview on humor in musical compositions in the classical and later periods is given in the introduction, as well as some information on the emergence of humorous 'genres' - as the authors call it - like Humoresque, Scherzo and Badinerie. As the authors mention, one could not make certain claims about the composers' intention of portraying certain emotions in their music with specific figures or articulations; however, the consideration of music theory prescriptions from earlier epochs, seems like a more promising strategy to achieve the goal of decoding composers' intentions. Throughout the ages, compositional treatises determined the use of musical figures for portraying certain emotions and the associated expressions like sighing, calling, crying or yearning (Mattheson, 1739; Vickers, 1984; Wessel, 1955). Haydn, Schumann and Dvořák, who are mentioned in the paper, most likely knew those common techniques well. It is questionable whether even modern composers are so strongly influenced by the earlier theory of musical figures; for this reason, it would be worthwhile to investigate whether there are differences in the use of staccato passages in older and newer compositions.

In part two of the study, a sample of 300 works - half of them being Scherzos, Humoresques and Badineries - were examined for the frequency of staccato passages. The selection process is well documented and detailed. After such a careful selection, it is surprising to see the great differences in length and duration at the end. This is very likely to affect the frequency of found staccato passages. However, an almost similar number of identified staccatos in humorous and other pieces does not necessarily contradict the distinct use of staccato to portray laughter in Scherzos, Humoresques or Badineries. In less humorous pieces, those passages most likely have different functions or display different meanings or emotions.

The method used by Trevor and Huron is an inspiring development, and may also be used to identify and compare other musical figures or articulations that are said to portray a variety of emotions. It is a lot of work, but can deliver rewarding results.

In the first part of the study, the authors attempted to find out in a listening test whether subjects consider a series of musical sounds to resemble realistic laughter when the tempo and duty cycle matches those of real human laughter. Three instrumental sounds (cello, horn and flute) and one female syllable ('ha') were used to produce a repetition that could be adjusted by the participants in volume, repetition rate and duty cycle. The basic playing technique of the three instrumental samples is not documented, but to adjust the duty cycle, longer lasting sounds than staccatos must have been used.

The results are surprising but quite interesting. Bearing in mind that the musical expression of emotions is often exaggerated, one would expect that the portrayed laughter in musical pieces is more 
pronounced and thus slower in tempo. But the subjects were asked to adjust the sound repetitions to emulate laughter that sounds realistic. Since all subjects had a background in music theory, one must ask whether their expertise could have influenced the results in this direction. It would be interesting to see the results for that experiment from a group with no musical training or expertise. One could also do another experiment with the average tempo and duty cycle as adjusted in this experiment, compared to the same sounds adjusted with the expected tempo and duty cycle from real laughter, and ask which version is rated as more realistic.

There is a lot a literature on specific instruments and registers that are most useful to produce grotesque, humorous or amusing sounds. 'Humoristic effects' are mentioned often for woodwind instruments, most notably the English horn (Rogers, 1970, p. 37), clarinet (Höfer, 1913, p. 33 \& p. 45), and the bassoon, which is often called 'the clown of the orchestra' (Kennan, 1962, p. 85). Höfer and Kennan both specifically mention the use of staccato for these effects.

Hauser (1996, p. 482) suggests that children for instance produce at least four types of laughter, with 'rhythmical laughter' being just one type. One could question if the regularity of rhythm is so important in the recognition of laughter, compared to timbral features such as formants.

The participants wish for pitch adjustment, however, is understandable. Interesting sample libraries can be found (ProjectSAM B.V., 2018), containing a variety of 'instrumental laughter' from different instruments in nearly all registers, that could be used for future experiments, when it comes to portraying realistic laughter. Using sample libraries, a variety of additional parameters could be adjusted, such as upward or downward slopes, pitch, envelope and many more.

The reported studies show two completely different aspects of the topic, uniting the fields of music psychology, music perception, music theory, practice, and even acoustics. Both parts of the paper are well documented, significant and non-significant results are discussed equally, the statistical methods used are robust. Possible sources of error are identified and discussed. With their investigations, Trevor and Huron succeed in gaining new insights, but also inspire new ideas for further, similar studies. The approach is useful and will likely result in more research in the future.

\section{ACKNOWLEDGEMENTS}

This article was copyedited by Scott Bannister and layout edited by Kelly Jakubowski.

\section{NOTES}

[1] Correspondence can be addressed to: Dr. Jörg Helmut Mühlhans, Institut für Musikwissenschaft, Universität Wien, Spitalgasse 2-4, AAKH, Campus Hof 9, 1090 Wien, Austria. joerg.muehlhans@univie.ac.at.

\section{REFERENCES}

Hauser, M. D. (1996). The evolution of communication. Cambridge, MA: MIT Press.

Höfer, F. (1913). Instrumentationslehre mit besonderer Berücksichtigung der Kirchenmusik [Instrumentation with special consideration of sacred music] Friedrich Pustet \& Co, Regensburg, Rom.

Kennan, K. W. (1962): The technique of orchestration. Englewood Cliffs, NY: Prentice-Hall. Inc.

Mattheson, J. (1739). Der vollkommene Capellmeister [The perfect chapelmaster], Hamburg: Christian Herold.

ProjectSAM B.V. (2018). Symphobia Colours: Animator. Software retrieved from https://www.projectsam.com/Products/Symphobia-Colours/1438

Rogers, B. (1970). The art of orchestration. Principles of tone color in modem scoring. Connecticut: APP Greenwood Press. 
Vickers, B. (1984). Figures of rhetoric/Figures of Music? Rhetorica, 2(1), 1-44. https://doi.org/10.1525/rh.1984.2.1.1

Wessel, F.T. (1955). Affektenlehre in the Eighteenth Century. Dissertation Indiana University, Ann Arbor, UMI 1977. 